\title{
EDITORIAL
}

\section{CONGRESO DEL COLEGIO INTERAMERICANO DE RADIOLOGÍA}

Con ocasión del XXV Congreso del Colegio Interamericano de Radiología que se realizará en nuestro país, en mi calidad de Directora del Congreso y Past President de la Sociedad Chilena de Radiología me ha sido conferido el honor de escribir esta Editorial, gesto que agradezco y valoro.

Al asumir nuestra Sociedad el desafío de organizar el XXV Congreso del CIR, se propuso como objetivo principal imprimirle a este Congreso un sello único, haciendo de él, más que un anexo al Congreso Chileno, un encuentro del CIR y para el CIR. Nos propusimos que los radiólogos miembros del Colegio vieran en los Congresos del CIR el lugar natural de encuentro de la radiología interamericana: un espacio para aprender, para conocerse y para debatir sobre los desafíos que plantea el desarrollo de la especialidad en la región. Se planteó la necesidad de desarrollar un programa académico de primer nivel, con profesores de excelencia, miembros del CIR, conocedores de la realidad regional, sus desafíos y limitaciones. Pensamos que ésa es la mejor forma de conocernos, de demostrar que somos capaces de lograr grandes objetivos si trabajamos unidos y de estimular a las nuevas generaciones de radiólogos a ser cada vez mejores. Nuestro objetivo es colaborar para que los radiólogos regionales se sintieran orgullosos de pertenecer al Colegio y que los radiólogos chilenos se sintieran orgullosos de ser los anfitriones de este encuentro.

El Colegio Interamericano de Radiología es una organización creada hace 67 años, que en la actualidad reúne a las Sociedades Radiológicas de 23 países de América, el Caribe y la Península Ibérica. Su misión fundamental es promover, apoyar y estimular el desarrollo y perfeccionamiento de la especialidad en los países de la región, en todos sus aspectos, de forma armónica y homogénea, contribuyendo así al mejoramiento integral de la salud.

Para lograr el desarrollo de la especialidad se deben enfrentar desafíos tecnológicos, educacionales y gremiales. Los que hemos participado en Directorios de nuestra Sociedad sabemos que ésta no es tarea fácil, que se requiere de mucho esfuerzo, tiempo y dedicación y, que con gran frecuencia la magnitud del trabajo supera las reales posibilidades de acción. Para enfrentar estas dificultades, la generación de alianzas estratégicas entre pares con realidades similares resulta de gran utilidad, ya que permite sumar miradas y aunar esfuerzos. En este contexto, el CIR se presenta como un ente facilitador, una gran alianza entre Sociedades Radiológicas de países que tienen mucho en común y además un mismo objetivo. EI CIR debe, y puede, actuar como un organismo central, desde donde se generen recomendaciones y acciones concretas que ayuden a que las sociedades radiológicas que lo integran logren el desarrollo de la especialidad en sus respectivos países.

Esperamos cumplir nuestros ambiciosos objetivos y también las expectativas de todos los que han trabajado y compartido este proyecto. En forma muy especial, esperamos que este Congreso propicie la unión de los radiólogos de la región, fortalezca al CIR y a cada una de las Sociedades de Radiología que lo integran. 